\title{
Assessment of Dental caries status, Periodontal health and oral hygiene practices among two Populations of Moradabad city, India
}

\begin{abstract}
:
Background: Ever since the beginning of the universe mankind had struggled constantly for their livelihood, Moradabad is branded as the "Brass city" of India, which comprises of a large number of populations working in different industries. Objective: To assess and compare the oral health status of workers employed in brass industries with non industrial workers of Moradabad city. Methods: A total of 500 workers from each group aged 30-50 with 5 years working experience were selected through random sampling. Type III examination was performed by recording who oral health assessment form. To compare the proportion chi-square test was used. Mean values were compared using students t-test. SPSS version 15.0 was used for statistical analyses. Results: The prevalence of dental caries as Mean DMFT score was significantly higher in Non Industrial Group i.e. $3.57 \pm 2.74$ while it was $2.88 \pm 2.14$ in brass workers. Periodontal diseases were higher among production workers that belong to brass industries. The prevalence of Oral Mucosal Lesions was significantly higher among Production Workers. Bleeding was more pronounced in general population but calculus and pockets were seen more in brass workers. The requirement of prosthetic status was also more prevalent among industry subjects. Conclusion: The Oral health status of Brass Industry Workers was relatively poor with poor periodontal health when compared to General Population. Further studies of oral occupational disease should be conducted in order to check or confirm previous reports and to discover possible manifestations arising in new industries.
\end{abstract}

Key Words: Moradabad; Oral Health Status; Occupational Health; Dental Caries; $\mathrm{CPI}$; Workers.

\author{
Amit Tirth ${ }^{*}$, Vipul Yadav ${ }^{*}$ \\ Pradeep. S. Tangade*, \\ Ravishankar. T. L*, Sunil \\ Chaudhary ${ }^{\circledR}$ and Anmol Mathur \\ *Department of Public Health \\ Dentistry, Kothiwal Dental College \& \\ Research centre, Kanth Road, \\ Moradabad -244001, Uttar Pradesh, \\ India \\ @Department of Oral Medicine and \\ Radiology, ESI Dental College, Rohini, \\ New Delhi, India. \\ Corresponding Author: \\ Dr. Amit Tirth \\ Email: a_tirth@yahoo.co.in \\ (c) 2013 IJOSH All rights reserved. \\ DOI: http://dx.doi.org/10.3126/ijosh.v3i2.6312
}

\section{Introduction}

Health at work and healthy work environment are amongst the most valuable assets of individuals, communities and countries. In the light of rapid economic growth and industrial progress in our country, it becomes imperative that safety and health at the workplace be given its due importance. It is only recently that there has been a shift in approach to the problems of occupational health and safety. Instead of investigating accidents after they have occurred, taking a high toll of human life, it is now felt that preventing the occurrence of industrial disasters and occupational diseases is a much better idea. Industrial revolution has made rapid strides in expanding industrial activity worldwide providing scope in employment for many and thus improving the standard of living of the people [1]. Moradabad is branded as the "Brass city" of India, which comprises of the people working in these industries. Lifestyle plays an important role in maintaining the normal integrity and natural functioning of the body.

In day to day life people work and struggle for their livelihood.
The maximum hour's people work outside their house that constitutes the environment for them. It may help or detoriate the health of an individual. Thus occupational health is quite significant. Glass industry is one among them where thousands of workers are indulged for earning a quality of life. Many studies have shown that there is a high prevalence of dental caries in industrial workers [2,3]. Environmental hazards contribute to poor oral health in many occupations $[4,5]$.

\section{Methods}

The study done was a comparative survey in which the oral health status of brass factory employees were compared with non industrial workers i.e. the general population residing in Moradabad. A pilot study was conducted on 20 brass industry and non industrial workers to find out the feasibility of the study. Oral health status was assessed among them using WHO Oral Health Assessment Form 1997[6]. Based on the findings with standard error of $1 \%$, sample size was estimated as 500 in each group. Standardization was carried out to minimize the intra examination error. The investigator was trained and calibrated 
for recording the WHO oral health Performa for oral diseases. The periodontal examination was done according to CPI criteria. sixteen brass industries were enlisted by visiting each factory and 8 were picked up by simple random sampling lottery method. Non industrial workers were included from dental camps organized for general population in Moradabad district. A pre-designed questionnaire was used to collect demographic information. Ethical clearance was obtained from ethical committee of Kothiwal Dental College and Research Centre, Moradabad. Informed consent was also obtained from each worker before conducting clinical examination.

Statistical Analysis: Statistical tests were performed using Statistical Package for Social Sciences, version 15.0. To compare the proportion chi-square test was used. Mean values were compared using students-t test. $\mathrm{Cl}$ of the study was kept at $95 \%$ hence the $p$ value less than $0.05 \%$ denoted statistically significant.

\section{Results}

Among the non-industry workers $72.4 \%$ belong to $30-40$ years and $27 \%$ belong to $41-50$ years. Whereas in brass workers $80 \%$ comprises of $30-40$ years and nearly $20 \%$ forms $41-50$ years age group. The difference among the age group and type of industry is found to be significant. Table I Mean number. of decayed teeth in non-brass group $(2.54 \pm 2.00)$ was significantly higher as compared to brass group $(1.86 \pm 1.78)$. The mean number of

Table I Distribution of Study Population According To Type of Industry and Age Group

\begin{tabular}{|c|c|c|c|}
\multirow{2}{*}{ Age Group } & \multicolumn{2}{|c|}{ Type of Industry } & \multirow{2}{*}{ Total } \\
\cline { 2 - 4 } & Non Brass & Brass & \\
\hline Mean Age & $38.28 \pm 4.22$ & $37.30 \pm 4.20$ & $37.79 \pm 4.24$ \\
\hline $30-40$ & $362(72.4 \%)$ & $400(80 \%)$ & $762(76.2 \%)$ \\
\hline $41-50$ & $138(27.6 \%)$ & $100(20 \%)$ & $238(23.8 \%)$ \\
\hline
\end{tabular}

$\chi 2=7.962(\mathrm{df}=1) ; \mathrm{p}=0.005$

missing and filled teeth in non-industrial group was $0.75 \pm 1.920$ and $0.28 \pm 0.70$ whereas in brass group it was $0.77 \pm 1.31$ and $0.25 \pm 0.75$. Total Mean DMFT was $3.57 \pm 2.74$ in non-brass and $2.88 \pm 2.14$ in brass group which was significantly higher in nonindustrial group as compared to brass group $(p<0.001)$, table II.

Table II Mean DMFT Status in relation to type of industry

\begin{tabular}{|ccccc|}
\hline Variable & \multicolumn{2}{c}{ Type of Industry } & "t" & "p" \\
& Non-Brass & Brass & & \\
\hline Decayed & $2.54 \pm 2.00$ & $1.86 \pm 1.78$ & 5.717 & $<0.001$ \\
\hline Missing & $0.75 \pm 1.92$ & $0.77 \pm 1.31$ & 0.192 & 0.848 \\
\hline Filled & $0.28 \pm 0.70$ & $0.25 \pm 0.74$ & 0.661 & 0.509 \\
\hline DMFT & $3.57 \pm 2.74$ & $2.88 \pm 2.14$ & 4.467 & $<0.001$ \\
\hline
\end{tabular}

Among brass workers bleeding was highest with $49 \%$ of subjects among 30-40 years. The non-brass workers showed more bleeding as compared to brass workers. Pockets up to $5 \mathrm{~mm}$ were more in industry workers as calculus is prevalent among them shown in table III.

Table III Distribution of Study Population According to Type of Industry, Age and CPI

\begin{tabular}{|c|c|c|c|c|}
\hline CPI Score & \multicolumn{2}{|c|}{ Brass Worker } & \multicolumn{2}{c|}{ Non Brass Worker } \\
\hline Age (year) & $30-40$ & $41-50$ & $30-40$ & $41-50$ \\
\hline Healthy & $29(7.25 \%)$ & $4(4 \%)$ & $20(5.52 \%)$ & $8(5.79 \%)$ \\
\hline Bleeding & $196(49 \%)$ & $36(36 \%)$ & $201(55.52 \%)$ & $60(43.47 \%)$ \\
\hline Calculus & $135(33.75 \%)$ & $46(46 \%)$ & $127(35.08 \%)$ & $56(40.57 \%)$ \\
\hline $\begin{array}{r}\text { Pocket up to } \\
5 \text { mm }\end{array}$ & $38(9.5 \%)$ & $13(13 \%)$ & $14(3.86 \%)$ & $14(10.14 \%)$ \\
\hline Pocket $>6 \mathrm{~mm}$ & $2(0.5 \%)$ & $1(1 \%)$ & $0(0 \%)$ & 0 \\
\hline Excluded & $0(0 \%)$ & $0(0 \%)$ & $0(0 \%)$ & 0 \\
\hline
\end{tabular}

Adverse oral habits in both the groups were shown in table IV. There were 221 (44.2\%) subjects in non-brass industry and 269 $(53.8 \%)$ in brass industry group who had adverse oral habits like pan masala, gutkha etc. In association with CPI, it was seen that subjects with no adverse habits had significantly higher healthy periodontal status as compared to those with adverse oral habits $(p<0.001)$. Statistically the incidence of adverse oral habits was significantly higher amongst brass industry subjects. Majority of respondents in both groups used to clean their teeth once a day. Only $20(4.0 \%)$ subjects in non-brass group and $33(6.6 \%)$ subjects in brass group used to clean their teeth twice a day shown in table $\mathrm{V}$. Frequency of cleaning teeth after every meal was very low in both the groups. In majority of cases the prosthetic status was intact table VI. However, in brass industry subjects the proportion of patients who had received prosthetic rehabilitation $(n=186 ; 37.2 \%)$ was significantly higher as compared to non-brass $(n=115 ; 23 \%)$ group $(p<0.001)$. Prosthetic need was more in industrial workers as compared to general population. Need for one-unit of prosthesis was seen in $3(0.6 \%)$ non-brass and $27(5.4 \%)$ brass workers. Multi-unit prosthesis was also more among industrial workers i.e.122 $(24.4 \%) .(16.5 \%)$ of brass industry workers were seeking a Combination of one- and/or multi-unit prosthesis which was more in comparison to non industrial group. Table VII showed that requirement of prosthesis was more pronounced in brass industry subjects. Overall there was a significant difference in prosthetic need of two groups $(p<0.001)$.

Table IV Distribution of Study Population According Adverse Oral Habits (Smoking, Tobacco Chewing, Pan, Ghutka)

\begin{tabular}{|c|c|c|c|c|c|c|}
\hline \multirow{3}{*}{$\begin{array}{l}\text { Habits } \\
\text { No }\end{array}$} & \multicolumn{4}{|c|}{ Type of Industry } & \multirow{2}{*}{\multicolumn{2}{|c|}{ Total $n=1000$}} \\
\hline & \multicolumn{2}{|c|}{ Non-Brass $(n=500)$} & \multicolumn{2}{|c|}{ Brass $(n=500)$} & & \\
\hline & 279 & $55.8 \%$ & 231 & $46.2 \%$ & 510 & $51 \%$ \\
\hline Yes & 221 & $44.2 \%$ & 269 & $53.8 \%$ & 490 & $49 \%$ \\
\hline
\end{tabular}




\section{Discussion}

Health has evolved over the centuries as a concept from an individual concern to a world-wide social goal and encompasses the whole quality of life. Every work place is really a work environment where there are interactions between people and the chemical and physical demands involved with performing job [7]. The present study was a cross sectional study to assess the oral health status of brass industry workers, and general population of Moradabad city. A total of 500 brass factory employees were examined and compared with general population of same age group. In our study the mean DMFT score was significantly higher in non industrial group $3.57 \pm 2.74$ as compared to brass industry group $2.88 \pm 2.14$.

Table V Distribution of Study Population According to Type of Industry and Frequency of Cleaning Teeth

\begin{tabular}{|c|c|c|c|c|c|c|}
\hline \multirow{2}{*}{$\begin{array}{c}\text { Method of } \\
\text { cleaning }\end{array}$} & \multicolumn{5}{|c|}{ Type Of Industry } \\
\cline { 2 - 7 } & Non-Brass $(n=500)$ & Brass $(n=500)$ & \multirow{2}{*}{ Total $n=1000$} \\
\hline Once & 478 & $95.6 \%$ & 465 & $93.0 \%$ & 943 & $\begin{array}{c}94.3 \\
\%\end{array}$ \\
\hline Twice & 20 & $4.0 \%$ & 33 & $6.6 \%$ & 53 & $5.3 \%$ \\
\hline After every & 2 & $0.4 \%$ & 2 & $0.4 \%$ & 4 & $0.4 \%$ \\
\hline meal & & & & & & \\
\hline
\end{tabular}

$\chi 2=3.368(d f=2) ; p=0.186$

This could be possibly due to the higher frequency of sweet consumption, sticky food and poor oral hygiene practices among general population. The results were positively associated with the previous study conducted among Lebanese adults showed that the poor dietary habits including high consumption of sugar containing products were associated with dental caries [8]. In our study both factory employees and general population showed an increase in CPI scores and was observed with an increase in age, which was statistically significant. Higher proportion of patients with bleeding gums was seen in lower age group, whereas calculus and deeper periodontal pockets were more common in higher age groups for all the sextants.

Table VI Distribution of Study Population According To Type of Industry and Prosthetic Status

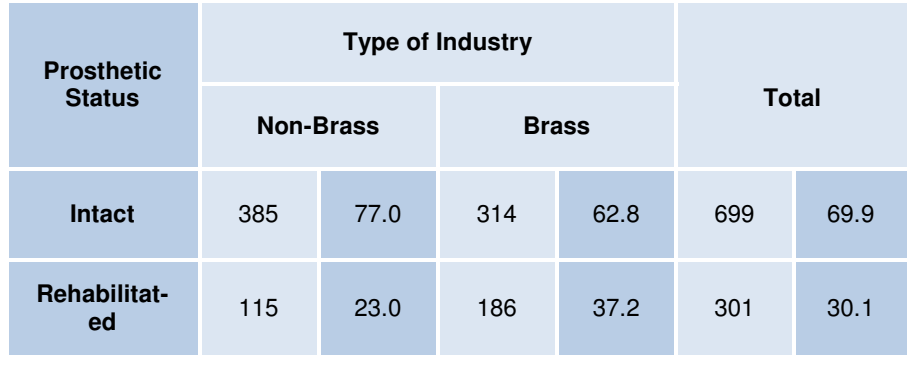

$\chi 2=23.959(\mathrm{df}=1) ; p<0.001$

Healthy scores were found in younger age groups, more bleeding was dominating among 30-40 years, and calculus was maximum in 41- 50 years. These findings were in conformity with a previous study on Finnish Industrial population showing the progression of periodontal disease with advancing age [9]. The study done on South Australian employees also showed that regression of periodontal status as age advances [10]. The results of our study were in correlance with the studies done on factory workers in Shangai, China [11] and Araraquara, in Brazil [12], Davangere city; Karnataka that calculus was the commonest score among industrial workers [13].

Poor life style is a significant factor in high prevalence of periodontal disease. Industrial workers constitute a well-defined

Table VII Distribution of Study Population According To Type of Industry and Prosthetic Need

\begin{tabular}{|c|c|c|c|c|c|c|}
\hline \multirow{3}{*}{$\begin{array}{c}\text { Prosthetic Need } \\
\begin{array}{c}\text { No prosthesis } \\
\text { needed }\end{array}\end{array}$} & \multicolumn{4}{|c|}{ Type Of Industry } & \multirow{2}{*}{\multicolumn{2}{|c|}{ Total }} \\
\hline & \multicolumn{2}{|c|}{ Non-Brass } & \multicolumn{2}{|c|}{ Brass } & & \\
\hline & 383 & $76.6 \%$ & 315 & $63.0 \%$ & 698 & $69.8 \%$ \\
\hline $\begin{array}{l}\text { Need for one-unit } \\
\text { prosthesis }\end{array}$ & 3 & $0.6 \%$ & 27 & $5.4 \%$ & 30 & $30.0 \%$ \\
\hline $\begin{array}{l}\text { Need for two-unit } \\
\text { prosthesis }\end{array}$ & 0 & $0 \%$ & 3 & $0.6 \%$ & 3 & $0.3 \%$ \\
\hline $\begin{array}{l}\text { Need for multi-unit } \\
\text { prosthesis }\end{array}$ & 90 & $18.0 \%$ & 122 & $24.4 \%$ & 212 & $21.2 \%$ \\
\hline $\begin{array}{l}\text { Need for a } \\
\text { combination of one } \\
\text { - and/or multi- } \\
\text { unit prosthesis }\end{array}$ & 24 & $4.8 \%$ & 33 & $16.5 \%$ & 57 & $5.7 \%$ \\
\hline
\end{tabular}

$c^{2}=23.959(d f=1): p<0.001$

A statistically significant difference was observed in the prosthetic status between the brass factory employees and the general population. In majority of cases ( $n=385$ in non-brass industry and $n=314$ in brass industry), the prosthetic status was intact. However, in brass industry subjects the proportion of patients who had received prosthetic rehabilitation $(n=186$; $37.2 \%)$ was significantly higher as compared to non-brass $(n=115 ; 23 \%)$ group $(p<0.001)$ table 6 . This might be due to higher percentage of factory employees that visited the dentist for replacement of teeth due to their access to dental check-up in their factories by dentists at regular intervals [18]. Requirement of prosthesis was more pronounced in brass industry subjects as compared to non-brass industry subjects showed in table 7. Overall there was a significant difference in prosthetic need of two groups $(p<0.001)$.

\section{Conclusion}

Oral health is considered not only the mirror of overall health of an individual but also a significant component of general health, hence oral health promotion needs to be integrated with the occupational service to improve oral health in industrial populations[19]. In conclusion good health practices were related to periodontal health. Subjects reporting poor health practices and unhealthy life style should be advised to change their habits to decrease their risk of developing periodontal disease. Further studies of oral occupational disease should be 
conducted in order to check or confirm previous reports and to discover possible manifestations arising in new industries [20].

\section{References}

1. Rajala M. Occurrence of tooth loss, dental caries and need of operative dental treatment in an industrial population. Kuopio: Publications of the University of Koupio. Community Health. Series Original Reports 2/1977. 103pp.

2. Petersen PE. Dental health behavior, dental health status and dental treatment needs among workers and staffmembers of a Danish shipyard: a socio-dental industrial investigation. Odense: Odense University Press, 1981.332pp.

3. Masalin KE, Murtomaa HT, Meurman JH. Oral health of workers in modern Finnish confectionary industry. Scand $\mathrm{J}$ Work Environ Health 1990; 18(3): 126-30.

4. Satoshi Shizukuishi, Naoji Hayashi et al. Life style and periodontal health status of Japanese Factory workers. Ann Periodontol1998;3:303-311.

http://dx.doi.org/10.1902/annals.1998.3.1.30

(PMid:9722714)

5. Lie T, Due NA, Boe OE. Periodontal health in a group of industrial employees. Community Dent Oral Epidemiol 1988; 16:42-6.

http://dx.doi.org/10.1111/j.1600-0528.1988.tb00553.x (PMid:3422618)

6. Ainamo J, Barmes D, Bergie G, Cutress T, Martin J, Sarbo Infirri J. Development of the World Health Organization (WHO) Community periodontal index and treatment needs (CPITN). Int Dent J. 1982; 32:281-291. (PMid:6958657)

7. Sakki TK, Knuuttila MLE, Vimpari SS, Kivela S. Lifestyle, dental caries and number of teeth. Community Dent Oral Epidemiol1994;22:298-302. http://dx.doi.org/10.1111/j.1600-0528.1994.tb02055.x (PMid:7813180)

8. A. Roman and A. Pop. Community Periodontal index and treatment needs values (CPITN) in a factory worker group in Cluj-Napoca, Romania. Int Dent J 1998; 48: 123-125. http://dx.doi.org/10.1111/j.1875-595X.1998.tb00470.x (PMid:9779093)

9. Mark Kannen Helena. Periodontal treatment need in a Finnish industrial Population. Community Dent Oral Epidemiol. 1978; 6(3): 240-244. (PMid:281289)

10. Srikandi TW, Carey SE, Clarke NG. Utilization of dental services and its relation to the periodontal status in a group of South Australian employees. Community Dent Oral Epidemiol.1983;11(2):90-94. http://dx.doi.org/10.1111/j.1600-0528.1983.tb01361.x (PMid:6573244)

11. Pilot T, Luzy ZO, Yen WP, Cao GR. Periodontal condition in 35-44 years old factory workers in Shanghai. Community Dent Oral $\quad$ Epidemiol.1989; 17(4): 216. http://dx.doi.org/10.1111/j.1600-0528.1989.tb00615.x (PMid:2758795)

12. Periodontal condition and treatment needs in a worker population in Araraquara, SP, Brazil. Int Dent J. 1994; 44 (4):309-11. (PMid:7822055)
13. Dr. Dharmashree S, Dr. Chandu GN, Dr. Pushpanjali. Periodontal status of industrial workers in Davangere city, Karnataka-A Descriptive Cross sectional study. Journal of Indian Association of Public Health Dentistry. 2006; 7: 2024.

14. Bergstrom J. Cigarette smoking as a risk factor in chronic periodontal disease. Community Dent Oral Epidemiol 1989; 17:245-247 http://dx.doi.org/10.1111//.1600-0528.1989.tb00626.x (PMid:2791514)

15. Kapoor AK, Ray SK, Kaur P, Reddy DCS, Nag Choudhary J. Dental caries and its relationship to materials used for cleaning teeth and frequency of cleaning teeth "Prevalence of dental caries". JIDA 1980; 52: 81-83.

16. Sakki TK, Knuuttila MLE, Vimpari SS, Hartikainen MSL. Association of life style with periodontal health. Community Dent Oral Epidemiol. 1995; 23:155-158. http://dx.doi.org/10.1111/j.1600-0528.1995.tb00220.x (PMid:7634770)

17. B. Doughan, Kassak K, Bourgois DM. Oral health status and treatment needs of 35-44 years old adults in Finland. Int Dent J. 2000; 50(6): 395-9. http://dx.doi.org/10.1111/j.1875-595X.2000.tb00575.x (PMid:11197200)

18. Masahide Imaki, Yukie Yoshida and Seiki Tanada. Relation between Smoking and Periodontal Disease by Oral Hygiene status in Japanese Factory Workers. Applied Human Science 1997; 16 (2) 2:.77-81.

19. I, Sarnat BG. Oral manifestations of occupational origin. Journal of American Medical Association 1942; 12: 11971207.

20. VV Doifode, NN Ambadekar and AG Lanewar. Assessment of oral health status and its association with some epidemiological factors in population of Nagpur, India. Indian J Med Sci 2000; 54:261-9 (PMid:11143844) 